\title{
Evaluation of Undergraduate Students' Involvement in Research Projects
}

Isabel Huet, University of Aveiro, Aveiro, Portugal

Ana Vitória Baptista, University of Aveiro, Aveiro, Portugal

Nilza Costa, University of Aveiro, Aveiro, Portugal

Alan Jenkins, Oxford Brookes University, UK

Marta Abelha, University of Aveiro, Aveiro, Portugal

\begin{abstract}
Major changes have been taking place in Higher Education (HE) systems, part of them emerging to face the demands of the so-called Bologna Process. Within this context, researchers show a great concern with issues that may promote the quality of students' learning. One of these concerns focuses on the importance of linking teaching and research in undergraduate studies since year one. A recent initiative of the Portuguese Ministry of Science, Technology and Higher Education is the creation of conditions to straighten this link by creating a set of research grants to undergraduate students, the so called BII ("Bolsas de Integração na Investigação"). The students can apply to these grants and get involved in research projects coordinated by senior researchers. At the University of Aveiro (Portugal), and in particular at the Department of Education, there are already undergraduate students engaged in several research projects, starting in the academic year 2008/09. Due to the novelty of these grants at Portuguese universities it is urgent to proceed to an evaluation process aiming to improve this initiative in subsequent years. Thus, the ultimate goal of this study is to (i) evaluate student outcomes of undergraduate research experience in Education; (ii) understand how the work developed is translated to European Credit Transfer System (ECTS), and (iii) identify the advantages and possible constrains of undergraduate students' involvement in research activities. In this paper the authors will explore in detail phase one of the study, more specifically how this initiative is taking place at the Department of Education, and the data referred to a questionnaire delivered at the beginning of the research process.
\end{abstract}

\section{Keywords: Higher Education, Linking Teaching and Research, Evaluation}

\section{Introduction}

Since the signature of the Bologna Declaration in 1999, certain issues, such as the quality of teaching, learning, assessment and research are acquiring a bigger relevance at Higher Education (HE) settings in Europe. In the European educational agenda there has been a strengthening idea concerning the importance and the need of promoting research both at under and postgraduate level. For instance, it becomes more essential to engage undergraduate students in research activities since the 1st cycle of Bologna.

Thus, discussions regarding the quality of research, of research supervision, and of students' involvement in research activities emerge as extremely important. Therefore, there is an increasing number of studies that focus on: (i) the importance of linking teaching and research 
in undergraduate studies, where the research-teaching nexus has become a recurrent theme (Jenkins et al., 2003); (ii) the evidence that more investigation is needed to study the impact of research in the students' experience and intellectual development (Jenkins, 2004); (iii) the definition of criteria that characterize an effective supervision practice and the roles of research supervisors (Pearson \& Brew, 2002; Kandlbinder \& Peseta, 2006; Park, 2005, 2007, 2008); and (iv) the experience and self-evaluation made by research students concerning their supervision experience (Harman, 2003) and the broader research experience.

In fact, we are witnessing the "transformation of academic work" (Enders, 2005, p.119), where the role of knowledge is also changing. This new and complex reality will have profound implications for research itself and for research supervision (Engebretson et al., 2008).

Consequently, several authors (Chambaz, Biaudet \& Collonge, n/d; Taylor, 2006; Vilkinas, 2008) emphasise a strong necessity of discussing the development of different set of skills and competences of research students and supervisors, essential to improve the quality of research practices since year one of undergraduate studies. This situation requires an emergent and growing awareness, within the academic community, of the necessity of possessing defined criteria and suitable instruments to evaluate the research process, both of research students' and supervisors' perspectives regarding under and postgraduate research initiatives.

Bearing in mind this generic background and also the pertinence and importance this subject is getting abroad and in Portugal - particularly due to the lack of national studies regarding the theme of this research - this paper will present: (i) a brief review of the state of the art and discussions on linking teaching and research, and the involvement of undergraduate students in research activities since year one; (ii) an overview of a study carried out at the

Department of Education at the University of Aveiro to monitor and evaluate the integration of undergraduate students in research activities; (iii) the data results of phase one of the study; and (iv) some final remarks regarding future lines of action.

\section{State of the Art}

"The recipients of the Integration into Research Grants (BII) are undergraduate students of higher learning (...) enrolled in (...) Portuguese institutions of higher learning and who demonstrate good scholastic performance. This type of grant is designed to foster scientific activity and the development of critical thinking skills, creativity and autonomy in students by integrating them into R\&D project teams." (FCT, 2008)

For many academics, national and institutional policy makers what distinguishes - or should distinguish - Higher Education is the interconnection between the teaching and the research roles of the university, and (undergraduate) students reaching new understandings of the complexities of knowledge through their learning in a research environment. However, the international research evidence suggests that the interconnection between teaching and discipline- based research, is not readily revealed in practice and, most significantly in the (undergraduate) student experience of the curriculum (Brew, 2006; Jenkins, 2004). A range of studies have shown that for many students their experience is of being excluded from research 
(Brew, 2006). For example Jenkins et al. (1998) carried out focus-group discussions with undergraduate students in a range of disciplines at Oxford Brookes University (UK). Students who perceived the involvement of academic staff in research as being incorporated into their teaching tended to see their courses as current and as stimulating intellectual excitement.

However, many students did not see themselves as stakeholders in university research. Internationally a range of studies using different research methodologies have confirmed these interpretations, in particular the Boyer Commission's (1998) critique of the US research elite institutions:

"The research universities have often failed, and continue to fail, their undergraduate populations, thousands of students graduate without seeing the world-famous professors or tasting genuine research." (Boyer Commission, 1998, p.3)

This research has been important in stimulating efforts to make undergraduate students more aware of research done by academic staff, but also in directing greater attention to make students explicitly participants in research and inquiry. Achieving this goal requires linked interventions at a range of levels from individual academics to departmental, institutional and national interventions (Healey \& Jenkins, 2009). It also means rethinking the curriculum from year one to the final graduating year. Internationally many institutions and national systems have embarked on this goal. Therefore, such interventions need to be researched as to their impact, in particular on the students understanding of research and their abilities to conduct research. Such interventions also raise critical questions as to what we mean by research from a student perspective.

In spite of recognising the long term goal to engage students in a research and inquiry based learning approach and the need to rethink the curricula based on this strategy, as previously referred, it is also important to promote other types of initiatives, such as the one described in this paper. The Portuguese Government, along with the Foundation for Science and Technology (FCT), decided to proceed with the creation of undergraduate research grants since 2008, the BII - "Bolsas de Integração na Investigação". This strategy underlines, therefore, one of the Bologna guidelines: the need for mobility and contact with diverse research realities, methodologies, subjects, institutional culture, policy and researchers. In fact, it is essential that the scientific activity begins as soon as possible, so that undergraduate students can be stimulated to develop critical thinking, creativity, autonomy and other transferable skills and competences not only during "regular" classes, but especially in research activities (Brew, 2007; Huet, Tavares, Costa, Jenkins, Ribeiro \& Baptista, 2008). On the other hand, it is also important to be aware of the students' perceptions about the meaning of doing research and above all to be integrated in research activities:

"We are all researchers now (...) teaching and research are becoming even more intimately related (...) in a 'knowledge society' all students - certainly all graduates have to be researchers. Not only are they engaged in the production of knowledge; they must be educated to cope with the risks and uncertainties generated by the advances of science" (Peter Scott, quoted by Jenkins \& Zetter, 2003, p.3) 
The previous citation underlines the importance of research initiatives: they have a profound implication on students' holistic development and engagement in academic, professional and personal conceptions and activities. Also, senior researchers benefit from this initiative, particularly in terms of their own personal and professional development, career progress and even the enthusiasm and credibility they may demonstrate to the students (Brown \& McCartney, 1998; Jenkins et al., 1998).

Still concerning this Portuguese initiative, all the research units and associated laboratories, both from public and private institutions, can open research grants in several projects. All undergraduate students can apply for a one year grant in any institution. At the end of the academic year (June-July), institutions present to the academic community the number and the subject of the research grants approved by the FCT. The selection period is made before holidays, so that in the beginning of the new academic year the undergraduate students may start the research grant. Although in the following year they can apply for another grant, they have to choose another institution or research unit. The selection of students is made by the institutions they apply for and the evaluation is based on specific criteria, particularly based on their academic success. Students will be supported by a qualified research supervisor and by the end of the grant, the student needs to write a report to be presented and discussed in a public session, organised by the foster institution. Moreover, the research units or associated laboratories may establish an agreement with the institution so that the learning outcomes achieved from the involvement on a specific research activity can be converted in ECTS.

Some other international and institutional interventions have been to create special "undergraduate research" programmes - in part stimulated by innovations at a range of US institutions - in particular the case of MIT. There are differences between those who see such programmes as being aimed at selected highly able students and those who argue such interventions should be aimed at all undergraduates. Relatedly:

"In the US much of the literature and practice sees undergraduate research as students having to produce original perhaps cutting-edge knowledge, suitable for publication in external refereed journals... Others, however, define or conceive undergraduate research as students learning through courses that are designed to be as close as possible to the research processes in their discipline. In these cases, what is produced and learned may not be new knowledge per se, but it is new to the student and, perhaps more significantly, transforms their understanding of knowledge and research." (Healey \& Jenkins, 2009, pp. 17-18)

In the USA undergraduate research was originally conceived as being for selected highly able and committed students in high ranking institutions such as MIT - though more recently such programmes have developed across a wide range of institutions. A particular stimulus to such selective programmes has been the perceived need to encourage highly able students into careers in the sciences. Organisations such as the National Science Foundation and the Howard Hughes Foundation have been particularly prominent in supporting such selective schemes in the sciences and in supporting research as to their effectiveness. A review of this research, which has developed a range of research methodologies, concludes that: 
"The literature converges on a broad set of benefits as arising from engagement in authentic research. Notably congruent are: gains in confidence and in establishing collegial working relationships with faculty and peers, increases in students' intellectual and practical understanding of how science research is done; students' greater ability to work and think independently from faculty; and the role of UR both in helping students to assess the fit of research as a career and to clarify career and graduate school plans. Across the studies, these results underscore UR experience as offering a constellation of gains that collectively reflect students' personal, intellectual and professional growth." (Hunter et al., 2010, chapter 2)

Such a conclusion provides support for the initiative at the University of Aveiro (UA). But, necessarily, we now need to research this initiative to both improve its effectiveness.

\section{The Study at the Department of Education at the University of Aveiro: An Overview}

The study has the objective to monitor and evaluate the integration of undergraduate students in research activities outside the classrooms. Since this is an innovative and recent strategy in Portugal it is crucial to understand the different phases of the study:

1. Phase one focused on the understanding of the initial expectations and motivations which led students to apply for the BII and to characterize students' conceptions of research;

2. Phase two focused on the evaluation of the supervision process, such as the guidance and support offered by the researcher responsible for the student, interaction between studentresearcher-student as well as to the evaluation of the on-going process of students doing research;

3. Phase three corresponding to the end of the grant, focused on the evaluation of the students' satisfaction as well as on how students' knowledge and experience have been translated to ECTS.

Phase one, which will be described in this article, was essential so that the authors could better understand how this new experience is being undertaken at the UA. The second and third phase will contribute to the reflection by researchers and students on their practice in order to improve some aspects that might be considered as less positive. It will be essential to evaluate all the process and, more particularly, to be aware of the changes occurred in the various phases in which the evaluation will be based on. This process may be seen as a way to enhance the quality of research and of the involvement of all agents in this process. Consequently, future editions of these grants may be improved. After phase two a Seminar at the Department of Education will be held aiming to discuss the previous issues, both with students and supervisors. The objective is that the evaluation process may be understood as a reflective and formative practice.

\section{Methodology}

Case study is an ideal methodology when a holistic, in-depth investigation is needed (Feagin,

Orum \& Sjoberg, 1991). Thus, this research method is most suitable, because it will analyse "a contemporary event that can not be manipulated" (Yin, 1994, p.8). Since this study is focused 
on "what" and "how" questions, this may be considered an exploratory and explanatory case study (Yin, 1994).

In phase one of the study, the authors followed three research questions:

- How do undergraduate students understand and conceptualize doing research in education?

What are undergraduate students' motivations to engage in research activities?

-What are the students' expectations about the research activities which they will join in?

To answer the previous research questions, a questionnaire with open answers was designed and delivered by mail to five students in the beginning of the research grant, even though one student (S1) had already started the work for about two weeks. The questionnaire had the next dimensions:

1. Perceptions about what is doing research in Education;

2. Motivations for joining the research activities: (a) in general and (b) in the specific project;

3. Expectations concerning the research, and more specifically related to (a) the type of investigation which will be developed; (b) the tasks which will be undertaken, and (c) the relevance of this work in the student academic path.

Bearing in mind the goal of the study and the type of instrument delivered, the data collected was qualitatively analysed. To better understand, systematise and discuss the results, we carried out a content analysis of the students' answers. We used a CAQDAS (Computer

Aided Qualitative Date Analysis Software): NVivo8. This software served as a catalyst for the review process, which promotes better employment, organization, search of patterns, systematisation of research and relationship of data across categories (Richards, 2002; Johnson, 2006). The categories which will be presented emerged from the data analysis.

Therefore, an interpretative perspective was adopted to present and discuss the data results of this case study that takes into account "particular individuals, focusing on their unique, individual 'insider' viewpoints" (Morey \& Luthans, 1984, p.30).

This evaluation study is carried out by researchers of the Laboratory for the Evaluation of Educational Quality in Higher Education (LAQE/ES), an organic research laboratory of the Research Centre of Didactics and Technology in Teacher Training (CIDTFF) of the Department of Education at the UA. This study was undertaken with the five undergraduate students who have obtained a research grant at the previous mentioned Department and their research supervisors. These undergraduate students were selected in July 2008 to engage in research activities in the academic year 2008-09.

More specifically, table 1 systematises the sample of this study: the theme of the projects, the gender and age of the five Bll students. All the five students are enrolled in the second year of the Basic Education Degree at the UA, with female students' predominance. 
Table 1: Demographic and Academic Characteristics

\begin{tabular}{|l|l|l|l|}
\hline Student & Gender & Age & Theme of the Project \\
\hline S1 & Male & 21 & $\begin{array}{l}\text { Construction and development of a blog about educa- } \\
\text { tional evaluation in the mass-media }\end{array}$ \\
\hline S2 & Female & 20 & $\begin{array}{l}\text { The "Science Garden": for a scientific culture in the } \\
\text { first years of schooling }\end{array}$ \\
\hline S3 & Female & 19 & $\begin{array}{l}\text { The project as a training strategy in Higher Education: } \\
\text { a case study in the Bologna context }\end{array}$ \\
\hline S4 & Female & 19 & $\begin{array}{l}\text { Evaluation of the curricular design in Higher Educa- } \\
\text { tion }\end{array}$ \\
\hline S5 & Female & 30 & $\begin{array}{l}\text { Construction and promotion of an online forum about } \\
\text { evaluation in education }\end{array}$ \\
\hline
\end{tabular}

\section{Data Results}

\section{Students' Perceptions about what is doing Research in Education}

At the beginning of the research grant, students understood that doing research in Education was:

- Updating information related to the educational context (referred by S1);

- Developing training and educational studies, analysing the results and finding proper educational methodologies which need to be more didactic, formative, attractive and efficient experiences aiming to have an implication in practice, namely in child development (referred by S2);

- Creating educational projects, analysing and developing a proper context to implement them (referred by S3);

- Designing the problem, collecting data, and planning, so that a decision is consciously made to solve the initial problem (referred by S4);

- Looking for means, mechanisms and information to improve educational contexts (referred by S5).

When reading students' perceptions, we became conscious that this is a complex question for them to answer. In fact, they reveal different perspectives about doing research, perhaps due to their academic and research experience. Also, their perceptions show that they are not used to be engaged in research activities: we must emphasise that this is the first year of implementation of these initial research grants (BII). Thus, their perceptions demonstrate their immature vision of being engaged in research activities. Therefore, it is important that senior researchers be enlightened by their answers and perceptions, so that they can (i) improve undergraduates' research experience, (ii) create an enriching research process, (iii) influence undergraduates' perspectives of research, and (iv) clarify, make students understand, "by doing", and develop intrinsically what is the meaning and dynamics of doing research in Education. 
We may then conclude that four students (S2, S3, S4, S5) understand "doing research" as a way to better understand a specific context in order to implement changes to enhance the quality of the educational context, and to develop certain aspects, more specifically the learning process and experience. The five students' perceptions point out the dynamics that the inquirybased learning intends to promote: the development of critical thinking, of problem-solving, and of autonomy and responsibility. As the literature underlines linking research and teaching can promote undergraduates' competences and skills. Also, in some points, even though students' perspectives need to be matured, they represent the first step towards students' involvement and understanding of doing research in the educational field, closer to what the literature points out.

\section{Motivations}

In the questionnaire there were two questions aiming to enlighten us about the reasons of application for (a) the research grant (BII), and (b) a specific project.

Concerning the first aspect, students mentioned different sorts of reasons which can be gathered in the next categories: (a) professional (referred by S1, S2, S3, S4, S5); (b) academic and formative (referred by S1, S2, S3, S4, S5); (c) personal (referred by S2, S3, S4, S5); and (d) financial, because this is a paid grant (referred by $\mathbf{S} 3$ ). In fact, most of students are motivated with the opportunity to enrich their personal curriculum and knowledge and to acquire professional experience as future teachers, trainers or researchers. Additionally, one of the students (S5) emphasises the importance of enlarging personal competences, skills and knowledge to face a demanding labour market.

Their answers to the question about the reasons for applying for the specific project were more homogeneous. All the students concentrate their focus on the specific subject which, for them, is embedded of great interest, involvement, enjoyment, pleasure and importance as far as the educational context is concerned. Also, they want to better understand the project in which they are involved in order to better work with the researchers of that field.

\section{Expectations}

Concerning the last dimension, we will focus on students' expectations regarding (a) the type of research, (b) the tasks they will be involved with, and (c) the relevance of the work for their academic path.

Once more, students' answers reveal their naïve perspective and involvement in research activities. As we have mentioned above, we may consider that undergraduate students are not used to express their expectations and motivations related to academic activities.

Considering students' expectations about the type of research, we highlight the perspectives stated by three students:

- S2 expects to give a contribution to the progression of the project in which she is engaged;

- S4 expects to observe and make some conclusions about the relationship between theory and practice;

- S5 expects to deepen her knowledge in the specific area of her project. 
The testimonies of the other two students reveal that this question was very complex and difficult for them to answer and for them to understand what was asked, because:

- There was a profound interconnection and even confusion between the expectations that students refer about the type of research and the tasks they will have to enrol with (referred by S2, S3). It becomes somewhat difficult for them to distinguish those two types of expectations, because, in most of the cases, they are alike;

- One of the students (S1) confused expectations with the experience he is already having.

Expectations were not mentioned, only a balance of the research experience was made.

In general, as far as tasks' expectations are concerned, students think (i) they will learn a lot, and (ii) those knowledge and skills will contribute to their professional career. There is a student (S2) who considers that the assignments/tasks will help her to know how a research activity works and how to actively participate on it. More specifically, students expect to:

- Analyse documents and also questionnaires that will be delivered in the project in which they are involved with (referred by S3);

- Search for appropriate information, read and select the adequate information (referred by S4, S5), so that the practical work will be suitably related to the theory. One of the students (S4) emphasises the importance of the theoretical part of the research work as a fundamental support of the empirical study.

The last question is focused on students' expectations about the relevance of the work in their academic path. Again, generic reasons for applying to the grant are observed. After the content analysis, the following categories emerged (table 2).

Table 2: Emergent Categories

\begin{tabular}{|l|l|}
\hline Categories & Description \\
\hline i & Professional training and experience \\
\hline ii & Personal development \\
\hline iii & Academic development \\
\hline iv & Research experience and knowledge \\
\hline
\end{tabular}

Consequently, we may systematise students' expectations about the relevance of the work in their academic path related to the previous mentioned categories (table 3): 
Table 3: Students' Expectations about the Relevance of the Work in their Academic Path Per Categories

\begin{tabular}{|l|l|}
\hline Categories & Students' expectations \\
\hline I & $\begin{array}{l}\text { S1 believes that he will improve certain techniques which may be useful } \\
\text { in the professional future, }\end{array}$ \\
and will have a different vision of educational research. \\
\hline Iv & $\begin{array}{l}\text { S2 considers that, being in contact with senior researchers will help her/him } \\
\text { to acquire and enrich her knowledge, and to become a more active and } \\
\text { scientifically informed person. }\end{array}$ \\
\hline iv & $\begin{array}{l}\text { S3 expects to contact with educational research projects in the area of } \\
\text { education. }\end{array}$ \\
\hline Iv & $\begin{array}{l}\text { S4 mentions that this experience may change her/his way of looking and } \\
\text { thinking about certain aspects of the educational system. }\end{array}$ \\
iii & $\begin{array}{l}\text { This student highlights that she will acquire and develop new skills and } \\
\text { competences related to the research methodology and work. }\end{array}$ \\
\hline $\begin{array}{l}\text { ii } \\
\text { iv } \\
\text { iii } \\
\text { i }\end{array}$ & $\begin{array}{l}\text { S5 believes this is an opportunity (a) to broaden personal horizons, comple- } \\
\text { menting her/his academic path with research activities; } \\
\text { and (b) to recycle knowledge and skills with which she can better respond } \\
\text { to the competitive and demanding labour market. The student also refers } \\
\text { that research in Education is essential to the development of human poten- } \\
\text { tial. }\end{array}$ \\
\hline
\end{tabular}

To conclude this aspect, we may say that, concerning these expectations, the five students mentioned, once more, the same reasons they had already pointed out when talking about their motivations (S1, S2, S3, S4, S5). However, they did not refer the development of specific academic skills or competences.

Final Considerations and Further Work

Considering the conclusions revealed by this phase of the study, we may emphasise that students' perceptions reveal naïve perspectives about what is doing research in Education. Therefore, it is indispensable that research activities such as the one described enhance students' research development, so they can be aware of what research effectively is and means in academic culture and life, and beyond it. It is also important that students realise how this experience enrich the development of competences, skills and attributes.

Bearing in mind the words of the students who have participated in this study, and although they were answering the questionnaire at the beginning of their research grant, they considered this as an opportunity to:

- Develop certain skills and competences;

- Acquire new knowledge, mainly in the field of the project in which they are involved with;

Contact with research in the field of Education;

- Be involved with senior researchers;

- Be personal and academic enriched; 
- Gather professional experiences.

Thus, HE institutions need to incorporate and develop a type of culture, practice and policy which value research activities, since year one of the 1st cycle of Bologna not only as in terms of this type of grants (linking teaching and research outside the classroom) but also as a methodology deeply connected with the teaching and learning process in the classroom. Finally, the authors are in the process of concluding phase two and three of the study. It is also planed to follow up the longer term impact of this intervention by interviewing these students in following years. Also, the same study needs to be replicated with students undertaking this undergraduate research programme in subsequent years and in other scientific domains. The results of these studies will contribute to the improvement of this programme and - depending on the results of such larger scale longer term studies - we will be more informed as to the value of such selective programmes. Whether they can and should be extended to the curriculum for more/many or even all students of course is a separate issue.

However, having strong data on the impact of selective programmes can help us to improve students' integration in research activities and perhaps extend it to all/many students as possible.

\section{References}

Boyer Commission on Educating Undergraduates in the Research University (2003). Reinventing undergraduate education: three years after the Boyer Report. Stony Brook: State University of New York at Stony Brook. Available from: www.sunysb.edu/pres/pdfs/0210066Boyer\%20Report\%20Final.pdf [last accessed 12 June 2009].

Brew, A. (2006). Research and teaching: beyond the divide. London: PalgraveMacmillan. Brew, A. (2007). Research and Teaching from the students' perspective. Available from: http://portallive.solent.ac.uk/university/rtconference/2007/resources/angela_brew.pdf [last accessed 12 June 2009].

Brown, R.B., \& McCarteny, S. (1998). The link between research and teaching: Its purpose and implications. Innovations in Education and Teaching International, 35(2), 117-129.

Chamaz, J., Biaudet, P., \& Collonge, S. (n/d). Developing the doctorate. Available from: http://phd.epfl.ch/webdav/site/phd/users/181668/public/Developing\%20the\%20Doctorate:\% 20Jean\%20Chambaz\%20et\%20al\%20on\%20doctoral\%20training\%20plans [last accessed in 13 January 2009].

Enders, J. (2005). Border crossings: Research training, knowledge dissemination and the transformation of academic work. Higher Education, 49, 119-133.

Engebretson, K., Smith, K., McLaughlin, D., Seibold, C., Terrett, G., \& Ryan, E. (2008). The changing reality of research education in Australia and implications for supervision: A review of the literature. Teaching in Higher Education, 13 (1), 1-15.

FCT - Fundação para a Ciência e Tecnologia (2008). Fellowships and Grants - 2008 Call for Applications to Integration into Research Grants for 5000 University-level Students. Portugal: 
Ministry of Science, Technology and Higher Education. Available from:

http://alfa.fct.mctes.pt/apoios/bolsas/concursos/BII2008.phtml.en [last accessed 12 June 2009].

FCT - Fundação para a Ciência e Tecnologia (2009). Regulations for Advanced Training and Qualification of Human Resources 2009. Portugal: Ministry of Science, Technology and Higher Education. Available from: http://alfa.fct.mctes.pt/apoios/bolsas/regulamento.phtml.en [last accessed 12 June 2009].

Feagin, J., Orum, A., \& Sjoberg, G. (eds.) (1991). A Case for Case Study. Chapel Hill, NC: University of North Carolina Press.

Healy, M., \& Jenkins, A. (2009). Developing undergraduate research and inquiry. York: The Higher Education Academy. Available from:

http://www.heacademy.ac.uk/assets/York/documents/resources/publications/DevelopingUnd ergraduate_Final.pdf [last accessed 20 June 2009]

Huet, I., Tavares, J., Costa, N., Jenkins, A., Ribeiro, C., \& Baptista, A. (2008). Strategies to Promote Effective Learning and Teaching in Higher Education. International Journal of Learning, Common Ground Publishers, 15 (10), 157-163, ISSN: 1447-9494.

Hunter, A-B., Laursen, S.L., Seymour, E., Thiry, H., \& Melton, G. (2010). Summer scientists: establishing the value of shared research for science faculty and their students. San Francisco: Jossey-Bass (in press).

Harman, G. (2003). PhD student satisfaction with course experience and supervision in two Australian Research-intensive Universities. Prometheus, 21 (3), 312-333.

Jenkins, A. \& Zetter, R. (2003). Linking Research and teaching in Departments. UK: LTSN Generic Centre. Available from:

http://www.ljmu.ac.uk/partnership/Collab_Partner_Docs/PF_Jan_07_Martyn_Stewart_RIT.pdf [last accessed 12 June 2009].

Jenkins, A. (2004). A guide to the research evidence on teaching-research relations. York: The Higher Education Academy. Available from:

www.heacademy.ac.uk/assets/York/documents/ourwork/research/id383_guide_to_research_ evidence_on_teaching_research_relations. pdf [last accessed 12 June 2009].

Jenkins, A., Breen, R., \& Lindsay, R., with Brew, A. (2003). Reshaping teaching in Higher Education: Linking teaching and research. A guide for academics and policy makers. London: Kogan Page.

Jenkins, A.J., Blackman, T., Lindsay, R.O., \& Paton-Saltzberg, R. (1998). Teaching and research: Student perceptions and policy implications. Studies in Higher Education. 23 (2), 127 41.

Johnston, L. (2006). Software and Method: Reflections on Teaching and using QSR NVivo in Doctoral Research. International Journal of Social Research Methodology, 9(5), 379-439. Kandlbinder, P., \& Peseta, T. (2006). In supervisors' words... An insider's view of postgraduate supervision. Sydney. The Institute for Teaching and Learning. 
Morey, N., \& Luthans, F. (1984). An emic perspective and ethnoscience methods for organizational research. Academy of Management Review, 9(1), 27-36.

Park, C. (2005). New variant PhD: The changing nature of the doctorate in the UK. Journal of Higher Education Policy and Management, 27 (2), 189-207.

Park, C. (2007). Redefining the doctorate. York. The Higher Education Academy. Available from: http://www.lancs.ac.uk/staff/gyaccp/RedefiningTheDoctorate.pdf [last accessed 13 January 2009].

Park, C. (2008). The end of the secret garden: Reframing postgraduate supervision. Available from: http://www.lancs.ac.uk/celt/celtweb/files/ChrisPark.pdf [last accessed 13 January 2009].

Pearson, M., \& Brew, A. (2002). Research training and supervision development. Studies in Higher Education, 27 (2), 135-150.

Richards, L. (2002). Rigorous, Rapid, Reliable and Qualitative? Computing in Qualitative Method. American Journal of Health Behavior, 26(6), 425-430.

Taylor, S. (2006). Developing and rewarding excellence in research supervision. Available from: http://www.hr.bham.ac.uk/development/courses/landt/Developing_and_rewarding_excellenc eHEA_06_paper.pdf [last accessed 13 January 2009].

Vilkinas, T. (2008). An exploratory study of the supervision of Ph.D./Research students' theses. Innovation in Higher Education, 32, 297-311.

Yin, R. (1994). Case Study Research: Design and Methods. Beverly Hills, CA: Sage Publishing.

\section{About the Authors}

Dr. Isabel Huet

Dr. Isabel Huet has a Ph.D. in Education and is currently a Research Fellow at the University of Aveiro in Portugal. Her research interests include new teaching and learning approaches with emphasis on engineering and science education, e-learning, collaborative learning, and linking teaching and research in Higher Education. Currently she is also interested on professional training of university teachers and the implications of the Bologna process in curricula design, teaching and learning.

\section{M.Ed Ana Vitória Baptista}

M.Ed Ana Vitória Baptista is a Ph.D Student at the University of Aveiro in Portugal. At the same time, she is finishing the writing of her M.Ed thesis, which is focused on a new public that is entering Higher Education (HE) Institutions: non-traditional adult students (or mature students). Her main interests include Higher Education policies; the Bologna Process and its consequences to HE Institutions, namely in the curricula, in the teaching and learning process, and in quality assessment and assurance; lifelong learning perspectives and discourses; nontraditional adult students; and postgraduate supervisory practice.

Prof. Nilza Costa 
University of Aveiro, Portugal

Prof. Alan Jenkins

Professor Emeritus on Higher Education, Consultant for the Higher Education Academy; Reinvention Fellow for the Reinvention Centre for Undergraduate Research: University of Warwick and Oxford Brookes University.

M.Ed Marta Abelha

University of Aveiro, Portugal 